Article

\title{
Organic Food Consumption in Italy: The Role of Subjective Relevance of Food as Mediator between Organic Food Choice Motivation and Frequency of Organic Food Consumption
}

\author{
Greta Castellini ${ }^{1,2, * \mathbb{D}}$, Mariarosaria Savarese ${ }^{1,2}$, Cinzia Castiglioni ${ }^{3} \mathbb{D}$ and \\ Guendalina Graffigna 1,2 \\ 1 Faculty of Agricultural, Food and Environmental Sciences, Catholic University of the Sacred Heart, \\ 26100 Cremona, Italy; mariarosaria.savarese@unicatt.it (M.S.); guendalina.graffigna@unicatt.it (G.G.) \\ 2 EngageMinds-HUB, Consumer and Health Engagement Research Center, 20123 Milano, Italy \\ 3 Faculty of Psychology, Catholic University of the Sacred Heart, 20123 Milano, Italy; \\ cinzia.castiglioni@unicatt.it \\ * Correspondence: greta.castellini@unicatt.it; Tel.: +39-0272343863
}

Received: 5 June 2020; Accepted: 1 July 2020; Published: 2 July 2020

\begin{abstract}
Nowadays, the problems that afflict our planet (climate change, loss of biodiversity, etc.) are leading to the implementation of a more sustainable type of consumption. Increasing the consumption of organic products is a way to face and try to solve these problems. In order to reach this aim, it is important to understand how consumers' subjective relevance of these products impacts on their consumption. The recent literature, in fact, highlighted how food consumption is salient for the individual to express their identity and life orientations, even more in the case of organic food consumption. Nonetheless, little is known about how subjective relevance of food affects organic food consumption. The present research aims to measure the role of subjective relevance in organic food consumption. Data were collected with a self-report questionnaire that was filled out by a sample of 964 Italians, representative of the population. We used structural equation modelling (SEM) and the bootstrap technique to test the hypothesis. The results show that subjective food relevance is a mediator between the motivations of organic food consumption and the frequency of consumption of it. This research points out the necessity to study consumers in a wider way, using communication that emphasizes the role that these products have in satisfying the psychological needs of consumers.
\end{abstract}

Keywords: subjective relevance; consumption motive; frequency consumption; organic food

\section{Introduction}

Sustainable food consumption is one of the three main domains that influence the management of sustainable development (the other two being housing and transportation [1,2]); a particularly relevant and urgent issue in this century [3]. In this regard, in recent years, consumers have changed their behavior and purchasing choices, favoring the consumption of sustainable food products in their daily diet [4]. In particular, consumers' concerns about the quality, safety, and environmental friendliness of foods have increased due to various food safety incidents and environmental issues $[5,6]$ that the European Union tries to prevent through a strong and clear legislative system $[7,8]$. These events have led to a greater consumer awareness of the possible pesticide residues in conventional foods, causing a decrease of credence in production methods [9] and, consequently, a raising of questions about modern agricultural practices as well as demand for organic foods [10] that has become the most popular sustainable consumption option among the various alternatives to conventional food [11]. 
In Italy, in particular, sales of organic products increased by $8 \%$ from 2017 to 2018, recording sales of 3.552 billion euros in 2018 [12]. The data are even more interesting if we expand the time window. Osservatorio Sana [12] observed that from 2001 to 2017, the signboards of large-scale distribution brands with a reference to organic foods increased by $144 \%$, and the average number of organic labels present in a large-scale retail store increased by $431 \%$. These are significant changes that show how a phenomenon that was initially considered a niche has turned into a habitual choice for many Italians. Moreover, Italians are known all over the world for their sophisticated culture of food. To Italians, the consumption of food is more than a way to satisfy physiological needs-it is an expression of cultural values and it has a strong psychological relevance [13]. In fact, in Italy, food has always been considered as a moment of sharing, with strong social relevance. In addition, the food choice is also considered as one of the main ways for Italians to express their identity and to respond to their personal needs [14]. In particular, the consumption of organic foods represents a way for Italians to respond to their ethical and food safety needs that appear to be stronger than all other countries [10].

Despite this increase in consumption and the relevance of it, it is necessary to promote, in a stronger way, the consumption of these products in order to boost the organic agriculture that could respond to the environmental problems that our planet is experiencing [15]. To encourage the consumption of organic food products, it is necessary to understand what are the personal levers that lead consumers to buy these types of food. In line with this purpose, this study aims to investigate what is the role of the subjective relevance of food in influencing the frequency of organic food consumption.

\section{Conceptual Framework and Hypothesis Development}

Most studies focused on understanding consumers' motivations for organic food consumption, highlighting that the main motives that lead consumers to prefer the organic foods are related to personal well-being, to the attention for animal health, and to the protection of the environment [16-20]. In particular, in a meta-analysis based on 150 studies on a total of 124,353 consumers, Massey et al. [21] noted that health, safety, quality, respect for the environment, and respect for animals are the main characteristics that consumers attribute to organic products and that distinguish organic from non-organic products. A study by Lockie et al. [22] showed that a slight increase in the importance of these reasons of consumption led consumers to double their purchase of these products, assuming that these types of motivations could be used to define "green" consumers and framing them in a broader concept of a "green lifestyle." Moreover, Ditlevsen et al. [23] claimed that the Danish consumers define organic food as healthy because it is considered pure, and this feature is the main motive that led the consumers to buy organic foods. In particular, Ueasangkomsate et al. [24] have made a list of the five main motives that determine the consumption of organic products, underlining how in the first position there is the local origin feature, followed by the animal welfare attribute and the environmental attribute. Health and food safety are the last two aspects that affect the intention to buy organic food products. Moreover, some authors demonstrated that naturalness, healthiness, respect for the natural environment, and animals are the main food motivations that lead people to personalize their food choices in order to satisfy their needs and express themselves [25-28]. Therefore, from these studies, it could be assumed that those who are driven by these motivations of consumption give much importance to food choices, considering them as a relevant aspect of their lives.

In line with these results, some studies claim that through the food choice it is possible to express the self-concept $[29,30]$ and to take care of personal health [31,32], becoming a possible key that drives and motivates consumers towards certain purchases rather than others. In support of this argument, previous studies also revealed that emotional and personal investment, beyond the motivation, is a fundamental aspect in orienting consumers' purchases [33-35]. With regard to organic food, it was demonstrated that a positive attitude towards these products is not enough to predict their purchase, but a high emotional involvement and a strong perceived relevance of these food products are necessary in order to generate the purchasing behavior [35,36]. It was also shown that those who give a strong subjective relevance of food, considering it as a fundamental way to take care of themselves or to 
express life orientation, are more prone to consume organic food, as a way to express their personal orientations [36-40]. The term "subjective relevance" is considered as a set of emotions and symbolic values that originate from human experience and that give meaning to reality [41,42]. Applied to the consumption of food, the concept of "subjective relevance" refers to the symbolic and emotional value of food in the individuals' subjective experience, which drives their consumption. In this study, in particular, we investigated the value that food has for people in terms of the expression of their personality and their life orientations.

From these premises, it is clear that the subjective relevance that people perceive towards food could be of extreme importance in explaining consumption behavior and, in particular, in defining the link between the motivations towards organic food consumption and the frequency of its purchase. In light of these considerations, we conducted the present study in order to verify two hypotheses:

Hypothesis 1 (H1). The motivation toward organic food choice positively influences the subjective relevance that people perceive towards food.

Hypothesis 2 (H2). The subjective relevance that people perceive towards food has a positive influence on the frequency of consumption of organic products.

Based on the above discussion, we can synthesize the hypotheses that inspired this study in the model depicted in Figure 1.

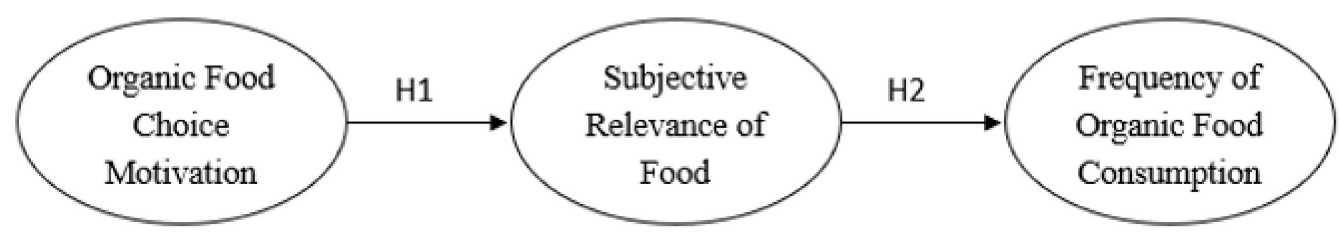

Figure 1. The hypothesized model.

\section{Materials and Methods}

\subsection{Procedure and Sample}

Research data were collected via a questionnaire that was inscribed by a representative sample of the Italian population, aged 18-75 years old, with sex, age, profession, size of the center, and geographical area extracted by stratified sampling. The percentages relating to the Italian population were taken from the website of the Italian National Institute of Statistics (ISTAT) [43]. In particular, the study was carried out in Italy because in this nation, more than others, the consumption of organic food has shown a positive trend, especially in the last years [44]. Moreover, a fairly recent review pointed out that the main drivers of consumption of organic food products in Italy are linked to ethical commitment and strong ethical values [10], evidence that underlines the necessity to understand to what extent the subjective relevance of food can make a difference in explaining this kind of consumption, especially in this nation. Every participant gave informed consent before taking part in this research. The survey was conducted using a CAWI (computer assisted web interviewing) methodology in the first three weeks of March 2019. The sample was made up of 964 subjects, of which 481 are male and 483 are female, aged between 18 and 75 years (Mean $=46$, Standard Deviation $= \pm 14.6$ ). The demographic profile is presented in detail in Table 1. This study has been performed in accordance with the Declaration of Helsinki and has been approved by an independent ethics committee of Catholic University of the Sacred Heart in Milan (CERPS). 
Table 1. Demographic profiles of the sample $(N=964)$.

\begin{tabular}{|c|c|c|c|}
\hline & $n$ & $\%$ & $\%$ Pop \\
\hline \multicolumn{4}{|l|}{ 1. Gender } \\
\hline Male & 480 & 49.7 & 49.3 \\
\hline Female & 484 & 50.3 & 50.7 \\
\hline \multicolumn{4}{|l|}{ 2. Age } \\
\hline $18-24$ & 92 & 9.6 & 10.0 \\
\hline $25-34$ & 144 & 15.0 & 15.3 \\
\hline $35-44$ & 178 & 18.5 & 21.0 \\
\hline $45-54$ & 214 & 22.2 & 22.7 \\
\hline $55-75$ & 336 & 34.8 & 31.0 \\
\hline \multicolumn{4}{|l|}{ 3. Education } \\
\hline Low school education & 123 & 12.8 & - \\
\hline High school education & 841 & 87.2 & - \\
\hline \multicolumn{4}{|c|}{ 4. Main household food purchaser } \\
\hline Yes, just me & 515 & 53.4 & - \\
\hline Yes, with others & 427 & 44.3 & - \\
\hline No & 22 & 2.3 & - \\
\hline \multicolumn{4}{|l|}{ 5. Geographic area } \\
\hline North-West & 254 & 26.3 & 26.3 \\
\hline North-East & 182 & 18.9 & 18.6 \\
\hline Centre & 190 & 19.7 & 19.7 \\
\hline South and Islands & 338 & 35.1 & 35.5 \\
\hline \multicolumn{4}{|l|}{ 6. Income level } \\
\hline Less than or equal to $€ 600$ & 34 & 3.6 & - \\
\hline$€ 601-900$ & 50 & 5.2 & - \\
\hline$€ 901-1200$ & 93 & 9.7 & - \\
\hline$€ 1201-1500$ & 144 & 14.9 & - \\
\hline$€ 1501-1800$ & 121 & 12.5 & - \\
\hline$€ 1801-2550$ & 174 & 18.1 & - \\
\hline$€ 2551-3550$ & 144 & 14.9 & - \\
\hline More than $€ 3550$ & 80 & 8.3 & - \\
\hline Missing & 124 & 12.9 & - \\
\hline \multicolumn{4}{|l|}{ 7. Profession } \\
\hline Employed & 643 & 66.7 & 67.3 \\
\hline Unemployed/retired & 321 & 33.3 & 32.7 \\
\hline \multicolumn{4}{|l|}{ 8. Inhabited center size } \\
\hline Up to 10,000 inhabitants & 462 & 47.9 & 48.0 \\
\hline $10,000-30,000$ inhabitants & 133 & 13.8 & 14.2 \\
\hline $30,000-100,000$ inhabitants & 147 & 15.2 & 16.6 \\
\hline More than 100,000 & 215 & 22.4 & 21.2 \\
\hline Missing & 7 & 0.7 & - \\
\hline
\end{tabular}

Note: Pop = population.

\subsection{Measures}

In this study, different kinds of validated scales and items were used ad hoc. We employed the following:

- Organic food choice motivation: We used the single-item Food Choice Questionnaire (FCQ) [45], which is composed of 12 items derived from the revision of Steptoe et al.'s [46] 36-item original FCQ. We selected four items that measure healthy, natural, animal welfare, and environmental motives (the main motivations for organic food consumption), creating a sub-scale called organic food choice motivation. All items were assessed on 7-point Likert scales ranging from 1 ("not at 
all important") to 7 ("very important"). An example of an item is: "It is important to me that the food I eat on a typical day is healthy."

- Subjective relevance of food: This is measured by four items that analyze the role that food has in consumers' self-expression and in consumers' lives. All items are measured on 7-point Likert scales ranging from 1 ("completely disagree") to 7 ("completely agree"). An example of an item is: "My food choices are a way to express myself."

- Frequency of organic food consumption: This behavior was assessed by the self-reported consumption frequency of organic products in the last month. The responses were assessed on a 5-point category scale from "never" to "every day". The single item used was: "In the last month, how many times have you consumed products with the word 'organic' on the label?" Many other studies have used the same item to assess the frequency of consumption [47].

\subsection{Data Analysis}

Descriptive statistics were computed for each item (asymmetry, kurtosis, mean, median, and standard deviation), and normality of the distribution was checked. In particular, asymmetry and kurtosis were reported to verify the normality of the different distributions while the mean and median were included in the analysis as measures of central tendency that allow us to better understand the distribution and to verify the possible outliers.

To evaluate the psychometric characteristics of the dimension of subjective relevance of food and the organic food choice motivation construct, we assessed the factor structure and reliability of constructs with a two-step procedure [48,49], randomly dividing the sample of 964 participants into two subsamples.

Factor analysis was performed on a subsample ( $N=609$, approximately $60 \%$ of the total sample) to estimate the factor loadings, to allow for greater accuracy of variable clustering, and to minimize the covariance between elements of factors [50].

Next, to check the adequacy of the items for the identified dimensions, a confirmatory factor analysis was run using MPLUS 8 on the second subsample of 355 (approximately $40 \%$ of the total sample). The models were estimated using the Satorra-Bentler correction (MLM) and evaluated using the chi-square (i.e., non-significant values associated with $p$ indicate a good model) and approximate fit statistics based on $\mathrm{Hu}$ and Bentler [51]. These included: root mean square error of approximation (RMSEA) < 0.08; confirmatory fit index $(\mathrm{CFI}) \geq 0.95$; and Tucker-Lewis index (TLI) $\geq 0.95$. Moreover, structural equation modelling (SEM) was used to analyze the relationships between the organic food choice motivation and subjective relevance of food on the frequency of organic food consumption. In particular, the bootstrap technique [52] was used to confirm the mediation hypothesis (the indirect relationship between an independent variable and the dependent variable considering the presence of the mediator) with more statistical rigor than the Sobel test and others $[53,54]$. Bootstrapping is a non-parametric technique that involves iteratively resampling a dataset with replacement. It allows one to generate an empirical representation of the sample distribution of the indirect effect by treating the obtained sample of amplitude $n$ as a representation of the population in miniature form. This method does not require the assumption of normality of the sample distribution, it provides high statistical power, and reduces the probability of type I error [52,55]. This procedure also allows a confidence interval to be obtained for the indirect effect based on bootstrap estimates. If the zero value is not between the lower and upper limit of the range, then the indirect effect is significant [52]. To investigate the indirect effects of the independent variable through the mediator, the percentile bootstrapping was performed at a 95\% confidence interval with 5000 bootstrap samples [56]. 


\section{Results}

\subsection{The Structure of Scales and Psychometric Properties}

Table 2 shows the means, standard deviations, medians, asymmetry, and kurtosis of subjective relevance of food (SRF) items, and Table 3 shows their inter-item correlations. Item SRF2 seems to have a non-normal distribution.

Table 2. Descriptive statistics for subjective relevance of food (SRF) items.

\begin{tabular}{cccccc}
\hline Item & M & SD & Md & A & K \\
\hline My food choices are a way to express myself (SRF1) & 5.17 & 1.24 & 5.00 & -0.54 & 0.49 \\
My food choices are a way to feel responsible for my life (SRF2) & 5.45 & 1.15 & 5.00 & -0.76 & 1.18 \\
I pay a lot of attention to my diet (SRF3) & 5.38 & 1.15 & 5.00 & -0.38 & 0.04 \\
Nutrition is a relevant theme for me (SRF4) & 5.50 & 1.14 & 6.00 & -0.55 & 0.27 \\
\hline
\end{tabular}

Note: Answering scale from $1=$ "completely disagree" to 7 = "completely agree"; $N=964 ; \mathrm{M}=$ mean; $\mathrm{SD}=$ standard deviation; $\mathrm{Md}=$ median; $\mathrm{A}$ = asymmetry; $\mathrm{K}=$ kurtosis.

Table 3. Inter-item correlations among subjective relevance of food items.

\begin{tabular}{ccccc}
\hline & SRF1 & SRF2 & SRF3 & SRF4 \\
\hline SRF1 & 1.00 & & & \\
SRF2 & $0.72^{* *}$ & 1.00 & & \\
SRF3 & $0.53^{* *}$ & $0.63^{* *}$ & 1.00 & \\
SRF4 & $0.53^{* *}$ & $0.62^{* *}$ & $0.75^{* *}$ & 1.00 \\
\hline$<0.01 ; N=964 ;$ SRF1, SRF2, SRF3, SFR4 are the subjective relevance of food items.
\end{tabular}

An exploratory factor analysis with oblimin rotation was performed on the first subsample $(N=609)$ to examine the factor structure. The analysis with an unconstrained number of factors yielded an eigenvalue of 2.51 with $62.8 \%$ of the variance explained. Thus, the exploratory factor analysis suggests that the subjective relevance of food is a one-dimensional variable $(\alpha=0.87)$.

Using the same sample, we also verified the structure and psychometric properties of the organic food choice motivation (OFCM) construct. Table 4 shows the means, standard deviations, medians, asymmetry, and kurtosis of OFCM items under analysis, and Table 5 shows their inter-item correlations. Item OFCM1 seems to have a non-normal distribution.

Table 4. Descriptive statistics for organic food choice motivation (OFCM) items.

\begin{tabular}{|c|c|c|c|c|c|}
\hline Item & $\mathbf{M}$ & SD & Md & A & K \\
\hline It is important to me that the food I eat on a typical day is healthy (OFCM1) & 6.10 & 1.13 & 6.00 & -1.60 & 3.38 \\
\hline It is important to me that the food I eat on a typical day is natural (OFCM2) & 5.88 & 1.09 & 6.00 & -0.89 & 0.63 \\
\hline It is important to me that the food I eat on a typical day is environmentally friendly (OFCM3) & 5.67 & 1.17 & 6.00 & -0.81 & 0.73 \\
\hline It is important to me that the food I eat on a typical day is animal friendly (OFCM4) & 5.69 & 1.23 & 6.00 & -0.92 & 0.80 \\
\hline
\end{tabular}

Table 5. Inter-item correlations among organic food choice motivation items.

\begin{tabular}{ccccc}
\hline & OFCM1 & OFCM2 & OFCM3 & OFCM4 \\
\hline OFCM1 & 1.00 & & & \\
OFCM2 & $0.65^{* *}$ & 1.00 & & \\
OFCM3 & $0.51^{* *}$ & $0.63^{* *}$ & 1.00 & \\
OFCM4 & $0.45^{* *}$ & $0.52^{* *}$ & $0.73^{* *}$ & 1.00 \\
\hline
\end{tabular}

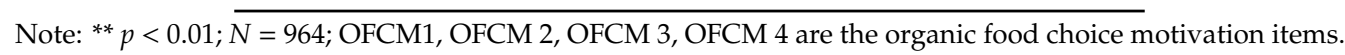

An exploratory factor analysis with oblimin rotation was performed to examine the factor structure. The analysis with an unconstrained number of factors yielded an eigenvalue of 2.69 with $67.21 \%$ of the 
variance explained. Thus, the exploratory factor analysis suggests that OFCM is a one-dimensional construct $(\alpha=0.84)$.

We also analyzed the means, standard deviations, medians, asymmetry, and kurtosis of the single item created to measure the frequency of consumption of organic foods, as shown in Table 6 . The distribution seems to be normal.

Table 6. Descriptive statistics for frequency of organic food consumption item.

\begin{tabular}{cccccc}
\hline Item & $\mathbf{M}$ & SD & Md & A & K \\
\hline $\begin{array}{c}\text { In the last month, how many times have } \\
\text { you consumed products with word } \\
\text { "organic" on the label? }\end{array}$ & 3.07 & 1.17 & 3.00 & -0.02 & -0.85 \\
\hline
\end{tabular}

Note: Answering scale from 1 = "Never" to 5 = "Every day"; $N=964 ; \mathrm{M}=$ mean; $\mathrm{SD}=$ standard deviation; $\mathrm{Md}=$ median; $\mathrm{A}$ = asymmetry; $\mathrm{K}=$ kurtosis.

The next step was to perform a confirmatory factor analysis on the second subsample $(N=355)$ to assess the reliability of the single variables using the MLM method. To determine goodness of fit, Beavers et al. [57] proposed that factor loadings $<0.40$ are weak, and factor loadings $>0.60$ can be considered strong. Moreover, the acceptable threshold value for composite reliability (CR) is above 0.70, while that for average variance extracted (AVE) is above 0.50 [58]. The results showed that the proposed models, as shown in Tables 7 and 8, provided a very good fit to the data and strong factor loadings. In the first model, the errors of two items (SRF1 and SRF2) were correlated (0.44), and in the second model, the errors of OFCM3 and OFCM4 were bound due to similarity in the formulation of items (0.52).

Table 7. Subjective relevance of food: confirmatory factor analysis and reliability indices.

\begin{tabular}{ccccccc}
\hline & & Standard Factor Loadings & SE & $p$ & CR & AVE \\
\hline \multirow{3}{*}{ Subjective } & SRF1 & 0.66 & 0.05 & $* * *$ & 0.86 & 0.61 \\
relevance of food & SRF2 & 0.75 & 0.04 & $* * *$ & & \\
& SRF3 & 0.88 & 0.03 & $* * *$ & & \\
& SRF4 & 0.84 & 0.04 & $* * *$ & & \\
\hline
\end{tabular}

Note: $(1){ }^{* * *} p<0.001 ; N=355$. (2) $\mathrm{X}^{2}=0.821 ; \mathrm{df}=1 ; p=$ n.s., confirmatory fit index $(\mathrm{CFI})=1.00$; Tucker-Lewis index $(\mathrm{TLI})=1.00$; root mean square error of approximation $($ RMSEA $)=0.00(\mathrm{LO} 90=0.00, \mathrm{HI} 90=0.13)$. (3) $\mathrm{SE}=$ standard error; $P=p$-value; $\mathrm{CR}=$ composite reliability; $\mathrm{AVE}=$ average variance extracted.

Table 8. Organic food choice motivation: confirmatory factor analysis and reliability indices.

\begin{tabular}{ccccccc}
\hline & Standard Factor Loadings & SE & $p$ & CR & AVE \\
\hline \multirow{3}{*}{ Organic food } & OFCM1 & 0.79 & 0.04 & $* * *$ & 0.85 & 0.59 \\
choice motivation & OFCM2 & 0.86 & 0.03 & $* * *$ & & \\
& OFCM4 & 0.74 & 0.05 & $* * *$ & & \\
& 0.66 & 0.05 & $* * *$ & & \\
\hline
\end{tabular}

Note: $(1)^{* * *} p<0.001 ; N=355 .(2) \mathrm{X}^{2}=0.225 ; \mathrm{df}=1 ; p=$ n.s.; CFI = 1.00; TLI = 1.00; RMSEA = 0.00 (LO90 = 0.00, $\mathrm{HI} 90=0.11)$. (3) $\mathrm{SE}=$ standard error; $P=p$-value; $\mathrm{CR}=$ composite reliability; $\mathrm{AVE}=$ average variance extracted.

\subsection{Model}

Finally, a structural equation model (SEM) was run in MPLUS 8 on the total sample $(N=964)$ to assess, firstly, the relationships between the organic food choice motivation and the frequency of organic food consumption and, secondly, the mediating role of subjective relevance of food between organic food choice motivation and the frequency of consumption.

The model without subjective relevance of food variable was tested, as shown in Figure 2. The model provided a quite good fit to the data: $X^{2}=21.561 ; \mathrm{df}=4 ; p=<0.001 ; \mathrm{CFI}=0.99 ; \mathrm{TLI}=0.97$; RMSEA $=0.07($ LO90 $=0.04$, HI90 $=0.09)$. 


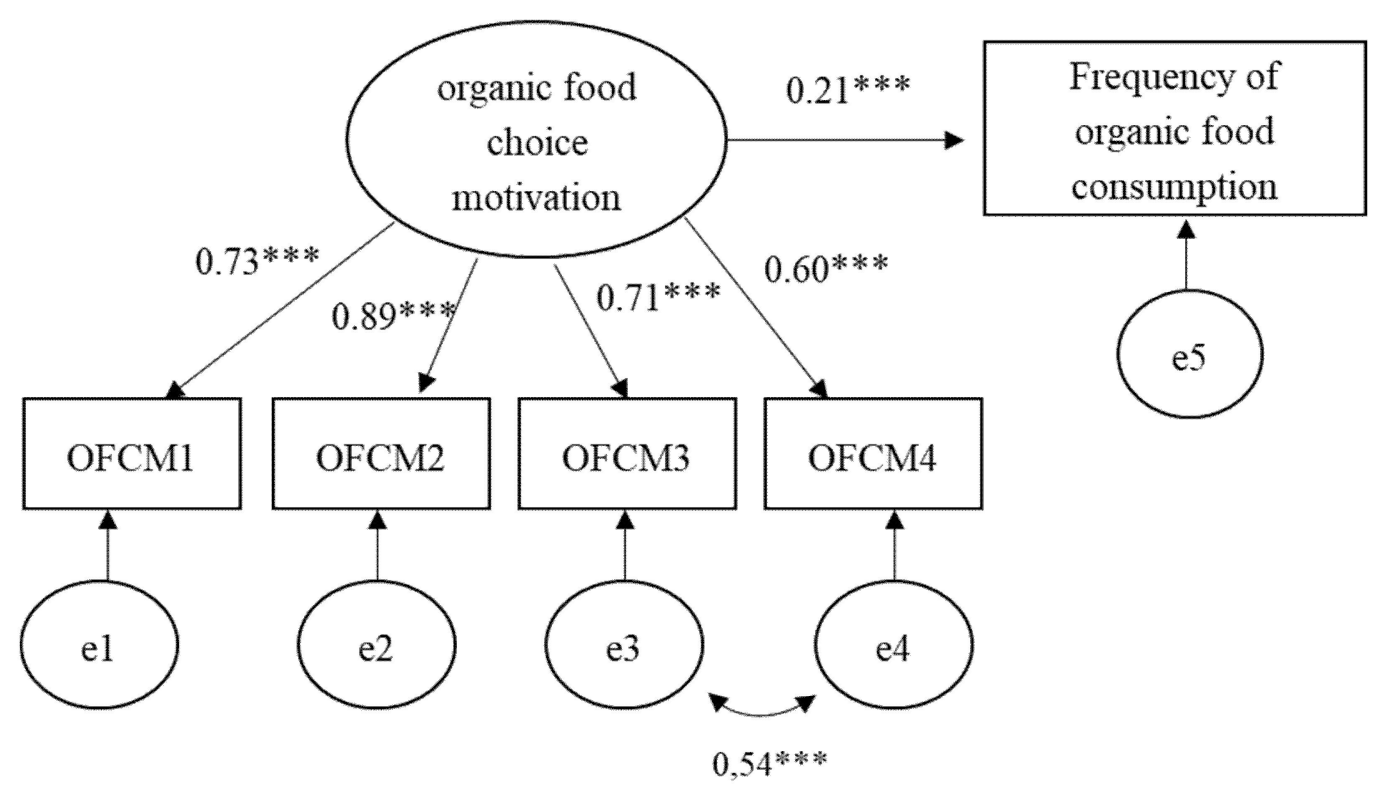

Figure 2. Relationships between organic food choice motivation and the frequency of organic food consumption. Standardized parameter estimates for the final model. Note: ${ }^{* * *} p<0.001 ; N=964$; $\mathrm{e}=$ error; OFCM1, OFCM 2, OFCM 3, OFCM 4 are the organic food choice motivation items.

Then, the dimension of subjective relevance of food was introduced as a mediator between organic food choice motivation and frequency of organic food consumption. The new model, as shown in Figure 3, provided an excellent fit to the data: $X^{2}=68.249 ; \mathrm{df}=24 ; p<0.001 ; \mathrm{CFI}=0.99$; TLI $=0.98$; RMSEA $=0.04$ (LO90 $=0.03$, HI90 $=0.05)$ and it is much better than the previous model, showing that the subjective relevance of food could improve the comprehension of organic food consumption. In accordance with the hypothesis, subjective relevance of food was positively influenced by organic food choice motivation $(\beta=0.64, p<0.001)$, confirming Hypothesis 2 , and the frequency of organic food consumption was positively influenced by subjective relevance of food $(\beta=0.28, p<0.001)$, confirming Hypothesis 1.

Finally, to verify the mediating role of subjective relevance of food between organic food choice motivation and the frequency of organic food consumption, percentile bootstrapping was performed at a $95 \%$ confidence interval with 5000 bootstrap samples [56]. Following the suggestions of Preacher and Hayes [53], the confidence interval of the lower and upper bounds was calculated to test whether the indirect effect was significant, as shown in Table 9.

Table 9. Standardized indirect effect of the model.

\begin{tabular}{|c|c|c|c|c|}
\hline & \multirow{3}{*}{ Point Estimate } & \multirow[b]{3}{*}{ S.E. } & \multirow{2}{*}{\multicolumn{2}{|c|}{$\begin{array}{c}\text { Bootstrapping } \\
\text { Percentile Bootstrapping 95\% CI } \\
\text { (Confidence Interval) of the Coefficients. }\end{array}$}} \\
\hline & & & & \\
\hline & & & Lower & Upper \\
\hline \multicolumn{5}{|l|}{ Total effect } \\
\hline $\mathrm{OFCM} \rightarrow$ frequency of consumption & 0.20 & 0.04 & 0.13 & 0.28 \\
\hline $\begin{array}{c}\mathrm{OFCM} \rightarrow \mathrm{SRF} \rightarrow \text { frequency of consumption } \\
\text { Direct effect }\end{array}$ & 0.16 & 0.03 & 0.09 & 0.23 \\
\hline OFCM $\rightarrow$ frequency of consumption & 0.05 & 0.05 & -0.05 & 0.15 \\
\hline
\end{tabular}

Note: (1) Mediator: subjective relevance of food. (2) Estimation of 5000 bootstrap sample. (3) SE = standard error; OFCM = organic food choice motivation; SRF = subjective relevance of food.

We note that the subjective relevance of food plays a mediating role (indirect effect $=0.16$, (Confidence Interval) $\mathrm{CI}=0.09 ; 0.23$ ) in the relationships between organic food choice motivation and frequency of organic food consumption. Moreover, the direct effect becomes insignificant (direct 
effect $=0.05, \mathrm{CI}=-0.05 ; 0.15)$ when the subjective relevance of food is used as a mediator and this indicates that subjective relevance of food plays a completely mediating role in the relationships between organic food choice motivation and frequency of organic food consumption.

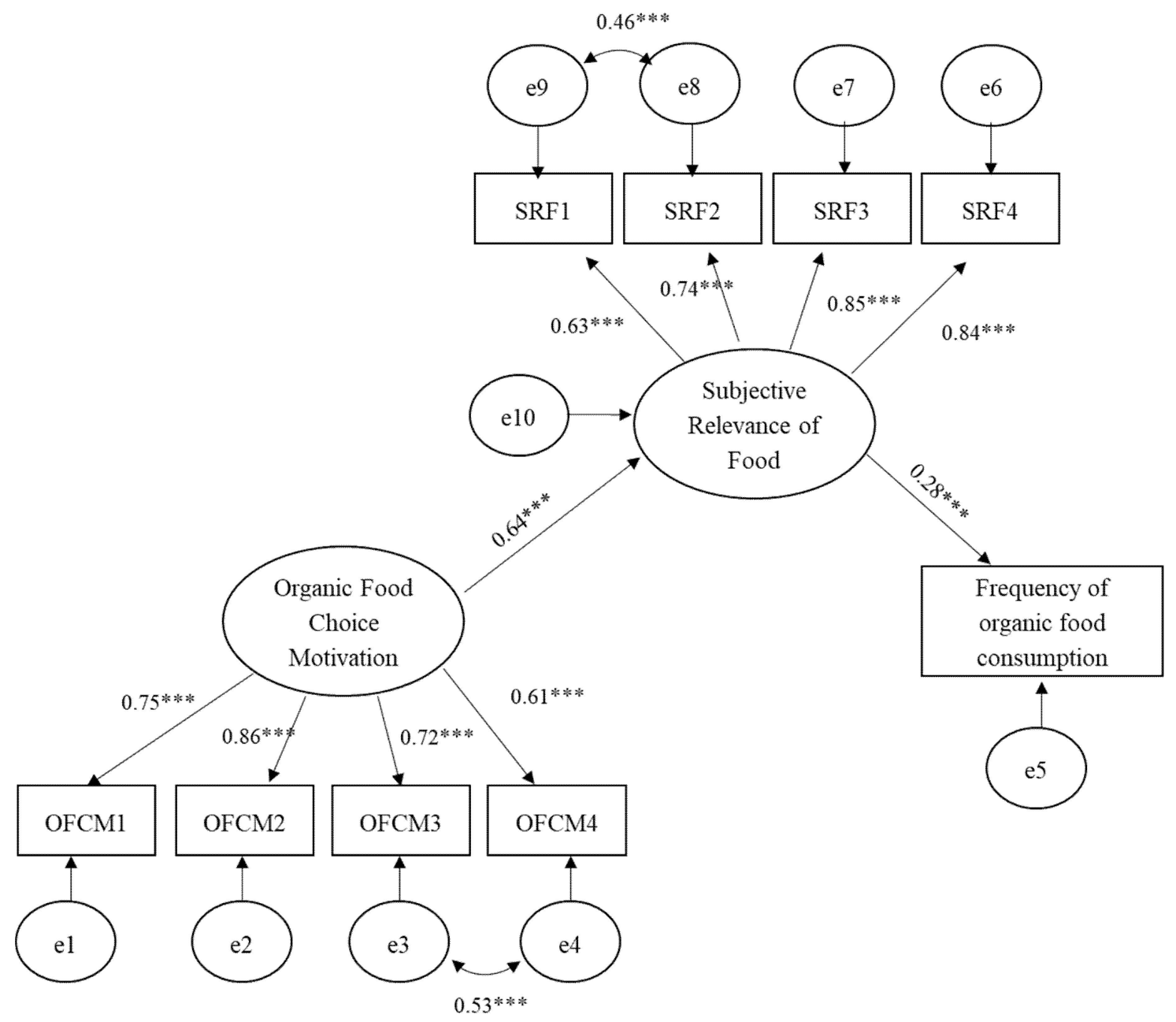

Figure 3. The mediating role of subjective relevance of food. Standardized parameter estimates for the final model. Note: ${ }^{* * *} p<0.001 ; N=964 ; \mathrm{e}=$ error; OFCM1, OFCM 2, OFCM 3, OFCM 4 are the organic food choice motivation items; SRF1, SRF2, SRF3, SFR4 are the subjective relevance of food items.

\section{Discussion}

In this research, it has been shown how the motivations related to health and the well-being of animals and environment significantly influence the subjective relevance that consumers give to food. This result was confirmed by other studies that have demonstrated how organic food involvement is affected by the personal, environmental, and animal well-being motivations $[35,59,60]$. Despite this, there is some research that shows contradictory results [61,62]. In particular, the main reasons that determine the consumption of organic food in Russia are not related to social issues (environmental or animal welfare) but mainly to personal well-being [63]. Furthermore, in Greece it was demonstrated that animal and environmental welfare does not affect the consumption of organic food [64]. In particular, research carried out in Denmark has observed that the egoistic motives (personal well-being) are dominant in respect to altruistic motives (the well-being of others) in influencing the consumers' organic food identity [65]. In addition, a recent review has considered how the motivations that determine the emotional involvement towards organic food change if we take into consideration developing and developed countries. In particular, it was shown that ethical commitment, quality, safety, and health 
are fundamental factors in the case of developed countries. On the contrary, the paramount factors in developing countries includes availability, education, health, marital status, and family size [10].

Moreover, in this paper, two different models were compared in order to explain the consumption of organic food. The first model related the motivations and the frequency of organic food consumption without considering the mediating effect of the subjective relevance that people perceive towards food, while the second model introduced the subjective relevance of food as a mediator between the motivations to consume organic foods and their consumption.

The results showed that the subjective relevance of food perceived by people is essential to better explain the consumption of organic foods, resulting in a full mediation between the motivations and the frequency of organic food consumption. These results confirm some previous studies that have argued that food consumption has a symbolic meaning beyond their functional utility; and part of this meaning is related to the need to express one's personality $[66,67]$ and to act on other spheres of one's life $[31,68]$. In the case of organic consumption, here proposed, this aspect appears particularly relevant, as the choice to consume organic foods could contribute to more sustainable consumption practices recommended today. These results about organic food are confirmed by some previous studies $[69,70]$ demonstrating that those who have strong health and ecological motivations perceived organic food as paramount to responding to their values and needs, being more prone to make efforts regarding the decisions of purchase (e.g., actively seeking information). In particular, the research carried out by Hansen et al. [65] has shown how organic food involvement was positively linked to both organic food identity and predisposition to buy organic food products. Moreover, the same study underlined how the organic food identity (defined as the perception of oneself as a consumer of organic products) influences the propensity to consume organic food, even if there are some mediators that affect the relationship between these two variables. Specifically, it has been observed that personal values and personality traits (e.g., levels of openness to change) mediate the relationship between the organic food identity and the intention to purchase organic food products. Moreover, our study has demonstrated that the subjective relevance that people perceive towards food can better explain the consumption of organic products than the food motivations and for this reason marketers and institutions should start taking into account the subjective relevance that consumers have of food in order to profile and to communicate with them in a more effective way. In line with these results, Van Huy et al. [71] argued that the different levels of interest in food affects the consumption of organic foods, underlining that those who seemed to be quite indifferent to food-related issues, in general, were less prone to purchasing organic foods.

Finally, these scientific results suggest that it is not enough to understand and use the consumers' motivations to encourage certain consumer behaviors, such as more sustainable consumption models, but it is essential to understand the role of psychological and subjective processing that characterizes the purchase of a product. In line with these results, some studies have shown that the degree of involvement with food in terms of values, symbols, and identities can significantly influence the consumption of some foods [72-74].

\section{Conclusions}

This study provides an overview of the aspects that affect the consumption of organic products, which is considered a key aspect to support sustainable consumption. We found that the motivations of healthiness, naturalness, and respect for animals and the environment are not enough to explain the purchase of organic products, but the subjective relevance that people perceive towards food is the paramount aspect in determining the consumption of organic products. This evidence points out the necessity to study consumers in a wider way, not only considering their food motivations, but also the subjective relevance that they perceive towards food. Moreover, this study gives a new contribution to existing theories as it underlines how the consumption of organic food is invested by a strong psychological value, which has been little considered in previous studies that mainly considered the motivations as the antecedents of the consumption of organic products. Finally, these findings 
show that, from a communicative point of view, marketers should not only emphasize the qualities of organic foods, but they should also leverage the subjective relevance of food that underpins these motivations for consumption by stressing the concept that "you are what you eat". In this manner, it is possible to emphasize the importance of organic food products, reinforcing the chances to orient present and future consumers to more sustainable practices [75]. However, it is not easy to influence the levels of subjective relevance of food and it may require a long-term and ambitious effort [76]. On the other hand, the companies that invested in organic food production could improve their profit by creating meeting or informatic platforms in which it is explained in a clear and transparent way how the company is committed to supporting the production of organic products, enhancing the sustainability and health qualities of them. By doing this, the consumers have the opportunity to recognize organic food as a product that can respond to their values and needs of safety, increasing the subjective relevance given to them and, consequentially, their consumption [77]. Furthermore, it appears evident how a psychological depth of understanding of consumers' processes of meaning towards their food choices is crucial in order to orient effective communicative strategies-studies able to give voice to the psychological relevance of an aliment within an individual's diet is important for advancing the knowledge of biological food consumption.

Although this research produced interesting results, it has some limitations. The frequency of consumption of organic foods is based on a self-reported item that does not allow for verification of the real consumption behavior. Moreover, the study assessed the psychometric properties of items related to subjective relevance of food, but it is necessary to evaluate also the psychometric validity of them. Finally, this study takes into account the consumer population of one society and culture. Although organic foods are known and sold in most countries, this could be a limitation of the generalizability of results when other countries are considered.

With regard to future research, it is important to underline that this study considered only three main predictors to explain the subjective relevance of food, but it could also be interesting to take into account other variables, such as personal characteristics (e.g., attitudes and values toward organic products) or some aspects related to the taste and price sensitivity, in order to better understand this construct. Moreover, future research may also explore how situational factors (e.g., social/peer influence) affect the subjective relevance of food, using socio-demographic features as a parameter of control. Finally, it may also be worth figuring out whether the subjective relevance of food affects in different ways the consumption of organic food according to the purchase/consumption channel used (e.g., restaurant, online shop, supermarket, etc.). In addition, this study was carried out in Italy, where food habits are traditionally culturally oriented and constitute an important pillar in citizens' life habits. It would be worthy to verify the stability of this evidence in other cultural settings with different food traditions.

Author Contributions: Conceptualization, G.C.; Methodology, G.C.; Formal analysis, G.C. and C.C.; Data curation, G.C. and C.C.; Writing—Original draft preparation, G.C.; Writing-Review and editing, M.S. and G.G.; Supervision, G.G. All authors have read and agreed to the published version of the manuscript.

Funding: This work was supported by the Fondazione Cariplo and Regione Lombardia within the CRAFT (Cremona Agri-Food Technologies) project, grant number: 2018/2757.

Conflicts of Interest: The authors declare no conflict of interest. The funders had no role in the design of the study, in the collection, analyses, or interpretation of data; in the writing of the manuscript, or in the decision to publish the results.

\section{References}

1. Steen-Olsen, K.; Hertwich, E.G. Life cycle assessment as a means to identify the most effective action for sustainable consumption. In Handbook of Research on Sustainable Consumption; Elgar: Cheltenham, UK, 2014; ISBN 9781783471270.

2. Tukker, A. Product services for a resource-efficient and circular economy-A review. J. Clean. Prod. 2015, 97, 76-97. [CrossRef] 
3. European Environment Agency (EEA)The European Environment-State and Outlook 2020: Knowledge for Transition to A Sustainable Europe; European Environment Agency: Copenhagen, Denmark, 2019; ISBN 978-92-9480-090-9.

4. Dowd, K.; Burke, K.J. The influence of ethical values and food choice motivations on intentions to purchase sustainably sourced foods. Appetite 2013, 69, 137-144. [CrossRef] [PubMed]

5. Hsu, C.L.; Chen, M.C. Explaining consumer attitudes and purchase intentions toward organic food: Contributions from regulatory fit and consumer characteristics. Food Qual. Prefer. 2014, 35, 6-13. [CrossRef]

6. Liu, R.; Pieniak, Z.; Verbeke, W. Consumers' attitudes and behaviour towards safe food in China: A review. Food Control 2013, 33, 93-104. [CrossRef]

7. Bondoc, I. European Regulation in the Veterinary Sanitary and Food Safety Area, a Component of the European Policies on the Safety of Food Products and the Protection of Consumer Interests: A 2007 Retrospective. Part One: The Role of European Institutions in Laying; Universul Juridic: Bucuresti, Romania, 2016; pp. 2-15.

8. Bondoc, I. European Regulation in the Veterinary Sanitary and Food Safety Area, a Component of the European Policies on the Safety of Food Products and the Protection of Consumer Interests: A 2007 Retrospective. Part Two: Regulations; Universul Juridic: Bucuresti, Romania, 2016; pp. 16-19.

9. Fernqvist, F.; Ekelund, L. Credence and the effect on consumer liking of food-A review. Food Qual. Prefer. 2014, 32, 340-353. [CrossRef]

10. Rana, J.; Paul, J. Consumer behavior and purchase intention for organic food: A review and research agenda. J. Retail. Consum. Serv. 2017, 38, 157-165. [CrossRef]

11. Asian, S.; Hafezalkotob, A.; John, J.J. Sharing economy in organic food supply chains: A pathway to sustainable development. Int. J. Prod. Econ. 2019, 7, 36-38. [CrossRef]

12. Osservatorio Sana. Available online: www.sana.it/media-room/archivio-news/osservatorio-sana-2018tutti-i-dati-sulle-abitudini-dacquisto-di-prodotti-bio-e-sulle-strategie-del-canale-specializzato/8843.html (accessed on 6 June 2019).

13. Poli, A.; Agostoni, C.; Graffigna, G.; Bosio, C.; Donini, L.M.; Marangoni, F. The complex relationship between diet, quality of life and life expectancy: A narrative review of potential determinants based on data from Italy. Eat. Weight Disord. 2019, 24, 411-419. [CrossRef]

14. Brunori, G.; Malandrin, V.; Rossi, A. Trade-off or convergence? The role of food security in the evolution of food discourse in Italy. J. Rural Stud. 2013, 29, 19-29. [CrossRef]

15. Skinner, C.; Gattinger, A.; Krauss, M.; Krause, H.; Mayer, J.; van der Heijden, M.; Mäder, P. The impact of long-term organic farming on soil-derived greenhouse gas emissions. Sci. Rep. 2019, 9, 1702. [CrossRef]

16. Akaichi, F.; Glenk, K.; Revoredo-Giha, C. Could animal welfare claims and nutritional information boost the demand for organic meat? Evidence from non-hypothetical experimental auctions. J. Clean. Prod. 2019, 207, 961-970. [CrossRef]

17. Laureti, T.; Benedetti, I. Exploring pro-environmental food purchasing behaviour: An empirical analysis of Italian consumers. J. Clean. Prod. 2018, 172, 3367-3378. [CrossRef]

18. Nie, C.; Zepeda, L. Lifestyle segmentation of US food shoppers to examine organic and local food consumption. Appetite 2011, 57, 28-37. [CrossRef] [PubMed]

19. Yazdanpanah, M.; Forouzani, M.; Hojjati, M. Willingness of Iranian young adults to eat organic foods: Application of the Health Belief Model. Food Qual. Prefer. 2015, 41, 75-83. [CrossRef]

20. Yin, S.; Wu, L.; Du, L.; Chen, M. Consumers' purchase intention of organic food in China. J. Sci. Food Agric. 2010, 90, 1361-1367. [CrossRef]

21. Massey, M.; O'Cass, A.; Otahal, P. A meta-analytic study of the factors driving the purchase of organic food. Appetite 2018, 125, 418-427. [CrossRef]

22. Lockie, S.; Lyons, K.; Lawrence, G.; Mummery, K. Eating "green": Motivations behind organic food consumption in Australia. Sociol. Rural. 2002, 42, 23-40. [CrossRef]

23. Ditlevsen, K.; Sandøe, P.; Lassen, J. Healthy food is nutritious, but organic food is healthy because it is pure: The negotiation of healthy food choices by Danish consumers of organic food. Food Qual. Prefer. 2019, 71, 46-53. [CrossRef]

24. Ueasangkomsate, P.; Santiteerakul, S. A Study of Consumers' Attitudes and Intention to Buy Organic Foods for Sustainability. Procedia Environ. Sci. 2016, 34, 423-430. [CrossRef]

25. Ares, G.; Gámbaro, A. Influence of gender, age and motives underlying food choice on perceived healthiness and willingness to try functional foods. Appetite 2007, 49, 148-158. [CrossRef] 
26. Honkanen, P.; Verplanken, B.; Olsen, S.O. Ethical values and motives driving organic food choice. J. Consum. Behav. 2006, 5, 420-430. [CrossRef]

27. Rankin, A.; Bunting, B.P.; Poínhos, R.; Van Der Lans, I.A.; Fischer, A.R.H.; Kuznesof, S.; Almeida, M.D.V.; Markovina, J.; Frewer, L.J.; Stewart-Knox, B.J. Food choice motives, attitude towards and intention to adopt personalised nutrition. Public Health Nutr. 2018, 21, 2606-2616. [CrossRef]

28. Sun, Y.H.C. Health concern, food choice motives, and attitudes toward healthy eating: The mediating role of food choice motives. Appetite 2008, 51, 42-49. [CrossRef] [PubMed]

29. Başar, E.E.; Türk, B.; Ünal, S. An investigation of self-image congruence differences between materialistic and non-materialistic consumers. Bogazici J. 2015, 29, 41-57. [CrossRef]

30. Vega-Zamora, M.; Parras-Rosa, M.; Torres-Ruiz, F.J. You Are What You Eat: The Relationship between Values and Organic Food Consumption. Sustainability 2020, 12, 3900. [CrossRef]

31. Czuber-Dochan, W.; Morgan, M.; Hughes, L.D.; Lomer, M.C.E.; Lindsay, J.O.; Whelan, K. Perceptions and psychosocial impact of food, nutrition, eating and drinking in people with inflammatory bowel disease: A qualitative investigation of food-related quality of life. J. Hum. Nutr. Diet. 2020, 33, 115-127. [CrossRef] [PubMed]

32. Saba, A.; Sinesio, F.; Moneta, E.; Dinnella, C.; Laureati, M.; Torri, L.; Peparaio, M.; Saggia Civitelli, E.; Endrizzi, I.; Gasperi, F.; et al. Measuring consumers attitudes towards health and taste and their association with food-related life-styles and preferences. Food Qual. Prefer. 2019, 73, 25-37. [CrossRef]

33. Conner, M.; McEachan, R.; Lawton, R.; Gardner, P. Basis of intentions as a moderator of the intention-health behavior relationship. Heal. Psychol. 2016, 35, 219-227. [CrossRef]

34. Keer, M.; Conner, M.; Van den Putte, B.; Neijens, P. The temporal stability and predictive validity of affect-based and cognition-based intentions. Br. J. Soc. Psychol. 2013, 53, 315-327. [CrossRef] [PubMed]

35. Teng, C.C.; Lu, C.H. Organic food consumption in Taiwan: Motives, involvement, and purchase intention under the moderating role of uncertainty. Appetite 2016, 105, 95-105. [CrossRef]

36. Nafees, L.; Das, N.; Hyatt, E.; Garber, L. Qualitative Insights into Organic Food: Perceptions of Indian and US Consumers: An Abstract. In Marketing Opportunities and Challenges in a Changing Global Marketplace, Academy of Marketing Science Annual Conference; Wu, S., Pantoja, F., Krey, N., Eds.; Springer: Cham, Switzerland, 2019; pp. 245-246. [CrossRef]

37. Lee, H.J.; Yun, Z.S. Consumers' perceptions of organic food attributes and cognitive and affective attitudes as determinants of their purchase intentions toward organic food. Food Qual. Prefer. 2015, 39, $259-267$. [CrossRef]

38. Onwezen, M.C.; Bartels, J.; Antonides, G. Environmentally friendly consumer choices: Cultural differences in the self-regulatory function of anticipated pride and guilt. J. Environ. Psychol. 2014, 40, 239-248. [CrossRef]

39. Shafie, F.A.; Rennie, D. Consumer Perceptions Towards Organic Food. Procedia Soc. Behav. Sci. 2012, 49, 360-367. [CrossRef]

40. Bai, L.; Wang, M.; Gong, S. Understanding the antecedents of organic food purchases: The important roles of beliefs, subjective norms, and identity expressiveness. Sustainability 2019, 11, 3045. [CrossRef]

41. González Rey, F. The topic of subjectivity in psychology: Contradictions, paths and new alternatives. J. Theory Soc. Behav. 2017, 47, 502-521. [CrossRef]

42. Hicks, J.A.; King, L.A. Meaning in Life as a Subjective Judgment and a Lived Experience. Soc. Personal. Psychol. Compass 2009, 3, 638-653. [CrossRef]

43. ISTAT Italian National Institute of Statistics. Available online: www.istat.it (accessed on 1 January 2019).

44. Nielsen Osservatorio immagino Nielsen GS1 Italy Le Etichette dei Prodotti Raccontano i Consumi Degli Italiani. Available online: https://osservatorioimmagino.it/ (accessed on 13 April 2020).

45. Onwezen, M.C.; Reinders, M.J.; Verain, M.C.D.; Snoek, H.M. The development of a single-item Food Choice Questionnaire. Food Qual. Prefer. 2019, 71, 34-45. [CrossRef]

46. Steptoe, A.; Pollard, T.M.; Wardle, J. Development of a measure of the motives underlying the selection of food: The food choice questionnaire. Appetite 1995, 25, 267-284. [CrossRef]

47. Chekima, B.; Chekima, K.; Chekima, K. Understanding factors underlying actual consumption of organic food: The moderating effect of future orientation. Food Qual. Prefer. 2019, 74, 49-58. [CrossRef]

48. Kinicki, A.J.; Jacobson, K.J.L.; Peterson, S.J.; Prussia, G.E. Development and Validation of the Performance Management Behavior Questionnaire. Pers. Psychol. 2013, 66, 1-45. [CrossRef]

49. Netemeyer, R.; Bearden, W.; Sharma, S. Scaling Procedures; SAGE: Thousand Oaks, CA, USA, 2012. 
50. Conway, J.M.; Huffcutt, A.I. A Review and Evaluation of Exploratory Factor Analysis Practices in Organizational Research. Organ. Res. Methods 2003, 6, 147-168. [CrossRef]

51. Hu, L.T.; Bentler, P.M. Cutoff criteria for fit indexes in covariance structure analysis: Conventional criteria versus new alternatives. Struct. Equ. Model. 1999, 6, 1-55. [CrossRef]

52. Preacher, K.J.; Hayes, A.F. Asymptotic and resampling strategies for assessing and comparing indirect effects in multiple mediator models. Behav. Res. Methods 2008, 40, 879-891. [CrossRef] [PubMed]

53. Preacher, K.J.; Hayes, A.F. SPSS and SAS procedures for estimating indirect effects in simple mediation models. Behav. Res. Methods Instrum. Comput. 2004, 36, 717-731. [CrossRef] [PubMed]

54. Shrout, P.E.; Bolger, N. Mediation in experimental and nonexperimental studies: New procedures and recommendations. Psychol. Methods 2002, 7, 422-445. [CrossRef] [PubMed]

55. MacKinnon, D.P.; Luecken, L.J. How and for Whom? Mediation and Moderation in Health Psychology. Health Psychol. 2008, 27 (Suppl. S2), S99-S100. [CrossRef]

56. Taylor, A.B.; MacKinnon, D.P.; Tein, J.Y. Tests of the three-path mediated effect. Organ. Res. Methods 2008, 11, 241-269. [CrossRef]

57. Beavers, A.S.; Lounsbury, J.W.; Richards, J.K.; Huck, S.W.; Skolits, G.J.; Esquivel, S.L. Practical considerations for using exploratory factor analysis in educational research. Pract. Assess. Res. Eval. 2013, 18, 1-13.

58. Fornell, C.; Larcker, D.F. Evaluating Structural Equation Models with Unobservable Variables and Measurement Error. J. Mark. Res. 1981, 18, 39-50. [CrossRef]

59. Chen, M.F. Consumer attitudes and purchase intentions in relation to organic foods in Taiwan: Moderating effects of food-related personality traits. Food Qual. Prefer. 2007. [CrossRef]

60. Hjelmar, U. Consumers' purchase of organic food products. A matter of convenience and reflexive practices. Appetite 2011, 56, 336-344. [CrossRef] [PubMed]

61. Zagata, L. Consumers' beliefs and behavioural intentions towards organic food. Evidence from the Czech Republic. Appetite 2012, 59, 81-89. [CrossRef] [PubMed]

62. Zakowska-Biemans, S. Polish consumer food choices and beliefs about organic food. Br. Food J. 2011, 113, 122-137. [CrossRef]

63. Bruschi, V.; Shershneva, K.; Dolgopolova, I.; Canavari, M.; Teuber, R. Consumer Perception of Organic Food in Emerging Markets: Evidence from Saint Petersburg, Russia. Agribusiness 2015, 31, 414-432. [CrossRef]

64. Chryssohoidis, G.M.; Krystallis, A. Organic consumers' personal values research: Testing and validating the list of values (LOV) scale and implementing a value-based segmentation task. Food Qual. Prefer. 2005, 16, 585-599. [CrossRef]

65. Hansen, T.; Sørensen, M.I.; Eriksen, M.L.R. How the interplay between consumer motivations and values influences organic food identity and behavior. Food Policy 2018, 74, 39-52. [CrossRef]

66. Hasselbach, J.L.; Roosen, J. Motivations behind Preferences for Local or Organic Food. J. Int. Consum. Mark. 2015, 27, 295-306. [CrossRef]

67. Govers, P.C.M.; Schoormans, J.P.L. Product personality and its influence on consumer preference. J. Consum. Mark. 2005, 22, 189-197. [CrossRef]

68. Lowden, A.; Moreno, C.; Holmbäck, U.; Lennernäs, M.; Tucker, P. Eating and shift work—Effects on habits, metabolism, and performance. Scand. J. Work. Environ. Heal. 2010, 36, 150-162. [CrossRef]

69. Padilla Bravo, C.; Cordts, A.; Schulze, B.; Spiller, A. Assessing determinants of organic food consumption using data from the German National Nutrition Survey II. Food Qual. Prefer. 2013, 28, 60-70. [CrossRef]

70. Thøgersen, J.; Jørgensen, A.K.; Sandager, S. Consumer Decision Making Regarding a “Green” Everyday Product. Psychol. Mark. 2012, 29, 187-197. [CrossRef]

71. Van Huy, L.; Chi, M.T.T.; Lobo, A.; Nguyen, N.; Long, P.H. Effective segmentation of organic food consumers in Vietnam using food-related lifestyles. Sustainability 2019, 11, 1237. [CrossRef]

72. Bruwer, J.; Cohen, J.; Kelley, K. Wine involvement interaction with dining group dynamics, group composition and consumption behavioural aspects in USA restaurants. Int. J. Wine Bus. Res. 2019, 31, 12-28. [CrossRef]

73. Burnier, P.C.; Spers, E.E.; Guerra, D. Effect of Production Process and Attitudes on the Intent to Buy Sustainable Beef. J. Int. Food Agribus. Mark. 2019, 1-27. [CrossRef]

74. Robinson, R.N.S.; Getz, D. Food Enthusiasts and Tourism. J. Hosp. Tour. Res. 2016, 40, 432-455. [CrossRef]

75. Richins, M.L. Measuring Emotions in the Consumption Experience. J. Consum. Res. 1997, 24, 127-146. [CrossRef] 
76. Aertsens, J.; Verbeke, W.; Mondelaers, K.; van Huylenbroeck, G. Personal determinants of organic food consumption: A review. Br. Food J. 2009, 111, 1140-1167. [CrossRef]

77. Barański, M.; Średnicka-Tober, D.; Volakakis, N.; Seal, C.; Sanderson, R.; Stewart, G.B.; Benbrook, C.; Biavati, B.; Markellou, E.; Giotis, C.; et al. Higher antioxidant and lower cadmium concentrations and lower incidence of pesticide residues in organically grown crops: A systematic literature review and meta-analyses. Br. J. Nutr. 2014, 112, 794-811. [CrossRef]

(C) 2020 by the authors. Licensee MDPI, Basel, Switzerland. This article is an open access article distributed under the terms and conditions of the Creative Commons Attribution (CC BY) license (http://creativecommons.org/licenses/by/4.0/). 